\title{
AGE ESTIMATION BY CORRELATION OF PHYSICAL AND DENTAL WITH RADIOLOGICAL FINDINGS
}

\author{
Trishul O. Padole1, Manish B. Shrigiriwar², Anil K. Batra3, Sachin J. Gadge4, Mahesh Sable \\ ${ }^{1}$ Assistant Professor, Department of Forensic Medicine and Toxicology, Government Medical College, Akola. \\ 2Professor and HOD, Department of Forensic Medicine and Toxicology, SVN Government Medical College, Yavatmal. \\ 3 Professor and HOD, Department of Forensic Medicine and Toxicology, Government Medical College, Akola. \\ ${ }_{4}^{4}$ Associate Professor, Department of Forensic Medicine and Toxicology, Government Medical College, Akola. \\ ${ }^{5}$ Assistant Professor, Department of Forensic Medicine and Toxicology, Government Medical College, Akola.
}

\section{ABSTRACT}

\section{BACKGROUND}

Age estimation is of paramount importance and requires special attention in medico-legal cases. In developing countries like India, because of illiteracy and ignorance regarding the importance of official records like birth and death, vast majority of population fail to give information of such vital events to the appropriate authorities entitled with these jobs. Determination of the age of an individual from physical findings, development of secondary sexual characteristics, dental status and the fusion of the ossification centres is a well-accepted fact in the field of Medical and Legal profession.

\section{MATERIALS AND METHODS}

The present study was carried out on 102 living subjects, (sample size was decided by pilot project), between the age group of 1070 years, brought to Dept. of Forensic Medicine \& Toxicology, SVN Govt. Medical College, Yavatmal for age determination. Age determination was done by correlation of Physical- Dental with Radiological findings by significantly minimising range in years. Each individual was examined for build, scalp hairs, axillary hairs, voice (in both sexes), prominence of Adam's apple, facial hairs, development of genitals (in males), and date of menarche, regularity of menses, breast development (in females) as per- Tanner stages of Breast development, Pubic hair growth for both sexes and Genital development for boys. The oral cavity was examined for number of teeth erupted and any abnormalities in dentition. X-ray of the oral cavity and various joints was taken. Pearson Correlation was used to assess correlation between age estimation by P4 computer using STATA 10.1, 2009 version software.

\section{RESULTS}

Very strong correlation (0.9104) observed between Reference age for pubic hairs and final age.

\section{CONCLUSION}

Height or weight alone cannot be considered as a good parameter for determination of age. Highly significant $p$-value ( $<<0.0001)$ was found between Tanner stages of pubic hair development compared with Physical-Dental age, Radiological age and Final age. Very strong correlation found between age estimated by Physical-Dental findings and Radiological findings. Parameters like secondary sexual characters, dental eruption status and ossification status, together gives more reliable estimation of age as compared to studying them individually.

\section{KEYWORDS}

Age Estimation, Correlation, Physical, Dental, Radiological Findings.

HOW TO CITE THIS ARTICLE: Padole TO, Shrigiriwar MB, Batra AK, et al. Age estimation by correlation of physical and dental with radiological findings. J. Evolution Med. Dent. Sci. 2017;6(94):6803-6807, DOI: 10.14260/jemds/2017/1473

\section{BACKGROUND}

Age estimation is important for identification of an individual as well as for unknown skeletal remains. Determination of individual's age is of great medico-legal importance in criminal cases, dowry deaths, juvenile cases, judicial punishments, commercial sex workers, etc. It is also required in admission to school, colleges, employment, marriages, etc.[1] Forensic Age Estimation defines an expertise in forensic medicine which aims to define in the most accurate way the chronological age of person of an unknown age involved in judicial or legal proceedings. ${ }^{[2]}$ Nowadays, there is

'Financial or Other Competing Interest': None.

Submission 02-11-2017, Peer Review 26-11-2017,

Acceptance 02-12-2017, Published 18-12-2017.

Corresponding Author:

Dr. Manish B. Shrigiriwar,

Professor and HOD,

Department of Forensic Medicine and Toxicology,

SVN Government Medical College, Yavatmal.

E-mail: manishmansi2004@hotmail.com

DOI: $10.14260 /$ jemds/2017/1473 no medical test or a group of tests that absolutely and accurately let us know the exact chronological age of a human being. [3] Nevertheless, in everyday practice, Justice Courts and other Public Institutions require reports (expert's) of Forensic physicians. In this expertise, there is a need of collaborative knowledge of very diverse disciplines like Forensic and Physical Anthropology, Odontology and even some general medical specialties like Radiology, all of them ideally centred in medical colleges. In old days, the eruption of second molar indicated the moment in which a young male was considered for military service.[4] During $19^{\text {th }}$ century, age estimation was mainly performed by dentists. In 1837, Edwing Saunders published "The Teeth a Test of Age" and British Parliament decided teeth eruption as an accurate method to determine the age of kids.[5]

In developing countries like India, because of illiteracy and ignorance regarding the importance of official records like birth and death, vast majority of population fail to give information of such vital events to the appropriate authorities entitled with these jobs. This causes paucity in such information when needed in a medico-legal case. In all 
those cases, Justice Courts and Public Institutions require forensic doctor's expert report. Determination of age is even more important in cases, where only skeletal remains are available for analysis, due to attempt made to dispose the body by mutilation, by dismemberment, by the use of corrosives, by the action of fire or in cases where murder was committed long ago. It is necessary sometimes to identify persons in mass disasters like earth quakes, floods, rail and air accidents, bomb explosions, etc. So we find that there are many methods of determination of age, out of these only commonly practised ones are, the noting of general physical examination, development and eruption of the tooth and the study of ossification of bones. It may be stated that none of those factors considered individually is of any value in the estimation of age. It is the sum total of these that must be taken into consideration. ${ }^{[6]}$

The most reliable and universally accepted scientific methods of estimation of age in living persons areDevelopment of secondary sexual characteristics, Observation of dental status, Radiological examination of diaphysioepiphysial union of long bones.

Study of indicators like secondary sexual characters, dental eruption status and ossification status, together gives more reliable estimation of age as compared to studying them individually. In present study, considering all these variables, we have made an effort to give the age of individuals as close as possible by correlation of physical and dental with radiological findings, which would be helpful in medico-legal cases.

\section{MATERIALS AND METHODS}

The prospective study was carried out on 102 living subjects, out of them 69 were male and 33 were female between age group of 10-70 years. All subjects were brought to Shri Vasantrao Naik Govt. Medical College, Yavatmal, for age determination from 2011 to 2013 (sample size decided by pilot project). The institutional ethical committee approval was obtained. The subjects who did not have any bony deformity or pathology, congenital malformation, nutritional deficiency, endocrinal disorders and chronic illness thus affecting the skeletal growth and development of the individual were taken in to the study. A written consent was obtained from the individuals personally above the age of 12 years. For individuals those who are below the age of 12 years, consent was taken from the parents, guardians or respective head of the institute (section 89 Indian Penal Code). A brief information of each individual including name, age, sex, occupation, address, name of accompanying Police constable/Person/Guardian, place, date and time of examination, two identification marks, birth date and education were recorded. In addition to this, two recent passport size coloured photograph and identity proof were also collected. Following parameters were Measured - height $(\mathrm{cm})$, weight $(\mathrm{kg})$, chest and abdominal circumference $(\mathrm{cm})$. Each individual was examined for build, scalp hairs, axillary hairs, voice (in both sexes), prominence of Adam's apple, facial hairs, development of genitals (in males), and date of menarche, regularity of menses, breast development (in females) as per- Tanner stages of Breast development, Pubic hair growth for both sexes[7] and Genital development for boys.[8] The oral cavity was examined for number of teeth erupted and any abnormalities in dentition. Space behind second molar tooth was assessed by putting a gloved finger over the gingival area just behind the tooth and was inferred to be present in cases where hard part of underlying bone was appreciated and was inferred to be absent in cases where only soft tissue was felt. In females it is generally seen at the age of 15-16 years, while in males it is seen after 16 years of age. Dental charting done by FDI (Federation Dentaire Internationale) method.[9,10] Radiological assessment of teeth was made by viewing X-ray films. X-ray of the oral cavity was taken as an oblique tangential view with the mouth open. The teeth were viewed mainly to examine the crown and root development.

After receiving radiological age report, final age certificate with attached photograph at the right corner was issued by correlation of physical- dental with radiological findings by significantly minimising range in years. Descriptive statistics were derived by using mean, standard deviation, frequencies, proportion and percentages. Inferential statistics were applied depending on the nature of variable. Pearson Correlation was used to assess correlation between age estimation by Physical and Dental with Radiological findings. Significance of difference was analysed with paired t-test. Statistical significance was considered as $\mathrm{p}<0.05$ and data was analysed by P4 computer using STATA 10.1, 2009 version software. The results obtained were compared with reference value available for same parameter, for correlation and $\mathrm{p}$ values. Critical evaluation of the results was done.

RESULTS

\begin{tabular}{|c|c|c|c|c|c|c|c|}
\hline \multirow{2}{*}{ Sex } & \multicolumn{6}{|c|}{ Age Group (in Years) } & \multirow{2}{*}{ Total } \\
\hline & $10-20$ & $21-30$ & $31-40$ & 41-50 & 51-60 & 61-70 & \\
\hline Male & 52 & 05 & 03 & 00 & 01 & 08 & 69 \\
\hline Female & 25 & 02 & 00 & 01 & 04 & 01 & 33 \\
\hline
\end{tabular}

Table 1. Comparisons Between all Age Variables of 102 Subjects between 10 to 70 years (n=102 including both sexes)

\begin{tabular}{|c|c|c|c|c|c|}
\hline & & Reported Age & Physical-Dental Age & Radiological Age & Final Age \\
\hline \multirow{2}{*}{ Reported age } & Pearson Correlation & 1.0000 & & & \\
\hline & P value & - & & & \\
\hline \multirow{2}{*}{ Physical-Dental Age } & Pearson Correlation & 0.9768 & 1.0000 & & \\
\hline & P value & 0.0001 & - & & \\
\hline \multirow{2}{*}{ Radiological age } & Pearson Correlation & 0.9843 & 0.9961 & 1.0000 & \\
\hline & P value & 0.0001 & 0.0001 & - & \\
\hline \multirow{2}{*}{ Final age } & Pearson Correlation & 0.9843 & 0.9965 & 0.9994 & 1.0000 \\
\hline & P value & 0.0001 & 0.0001 & 0.0001 & - \\
\hline & & $\begin{array}{l}\text { Values betwee } \\
\text { ( } n=102 \text { includ }\end{array}$ & $\begin{array}{l}\text { Age Variables (based } \\
\text { oth sexes) }\end{array}$ & values from Table & \\
\hline
\end{tabular}




\begin{tabular}{|c|c|c|c|c|c|c|c|}
\hline Variable & & Subjects & Mean & Standard Error & Standard Deviation & \multicolumn{2}{|c|}{ 95\% Confidence Interval } \\
\hline \multirow{2}{*}{ Observed } & Height $(\mathrm{cm})$ & 95 & 159.0435 & 2.214289 & 10.61936 & 154.4513 & 163.6356 \\
\cline { 2 - 8 } & Weight $(\mathrm{kg})$ & 95 & 49.6087 & 3.09771 & 14.85609 & 43.18444 & 56.03295 \\
\hline \multirow{2}{*}{ Reference } & Height $(\mathrm{cm})$ & 95 & 170.7826 & 2.43164 & 11.66173 & 165.7397 & 175.8255 \\
\cline { 2 - 8 } & Weight $(\mathrm{kg})$ & 95 & 61.82609 & 2.576614 & 12.35701 & 56.48252 & 67.16966 \\
\hline \multirow{2}{*}{ Difference } & Height $(\mathrm{cm})$ & & -11.73913 & 1.623953 & 7.788204 & -15.107 & -8.371258 \\
\cline { 2 - 8 } & Weight $(\mathrm{kg})$ & & -12.21739 & 2.372401 & 11.37764 & -17.13745 & -7.297333 \\
\hline
\end{tabular}

Table 3. Analysis of Mean, Standard error, Standard Deviation, 95\% Confidence Interval and Differences between Observed Height, Weight and Reference Height, Weight of 95 Subjects whose Reported Age were Available (n=95 including both sexes)

\begin{tabular}{|c|c|c|c|c|c|c|}
\hline & & $\begin{array}{c}\text { Reported } \\
\text { Age (Years) } \\
\end{array}$ & $\begin{array}{l}\text { Reference Age for } \\
\text { Pubic Hairs (Years) }\end{array}$ & $\begin{array}{c}\text { Physical- Dental } \\
\text { age (Years) }\end{array}$ & $\begin{array}{c}\text { Radiological } \\
\text { Age (Years) }\end{array}$ & $\begin{array}{c}\text { Final } \\
\text { Age (Years) }\end{array}$ \\
\hline \multirow{2}{*}{$\begin{array}{l}\text { Reported } \\
\text { Age (years) }\end{array}$} & Pearson Correlation & 1.0000 & & & & \\
\hline & P value & - & & & & \\
\hline \multirow{2}{*}{$\begin{array}{l}\text { Reference Age for } \\
\text { pubic hairs (years) }\end{array}$} & Pearson Correlation & 0.8456 & 1.0000 & & & \\
\hline & P value & 0.0001 & - & & & \\
\hline \multirow{2}{*}{$\begin{array}{c}\text { Physical- Dental } \\
\text { age (years) }\end{array}$} & Pearson Correlation & 0.8511 & 0.8831 & 1.0000 & & \\
\hline & P value & 0.0001 & 0.0001 & - & & \\
\hline \multirow{2}{*}{$\begin{array}{c}\text { Radiological } \\
\text { age (years) }\end{array}$} & Pearson Correlation & 0.8364 & 0.8702 & 0.9298 & 1.0000 & \\
\hline & P value & 0.0001 & 0.0001 & 0.0001 & - & \\
\hline \multirow{2}{*}{ Final age (years) } & Pearson Correlation & 0.8687 & 0.9104 & 0.9560 & 0.9626 & 1.0000 \\
\hline & P value & 0.0001 & 0.0001 & 0.0001 & 0.0001 & \\
\hline
\end{tabular}

Table 4. Correlation and P value between Reference age for pubic hairs with Reported age, Physical-Dental age, Radiological age and Final age of 39 Subjects between Age Group 10 to 16 Years (n=39 including both sexes)

\begin{tabular}{|c|c|c|c|}
\hline & & Physical-Dental Age (Years) & Dental Reference Age (years) \\
\hline \multirow{2}{*}{ Physical-Dental age (Years) } & Pearson Correlation & 1.0000 & \\
\cline { 2 - 4 } & P value & - & 1.0000 \\
\hline \multirow{2}{*}{ Dental reference age (Years) } & Pearson Correlation & 0.7782 & 0.0001 \\
\cline { 2 - 4 } & P value & Aable 5. Correlation and P value between Physical-Dental Age and Dental Reference \\
\hline \multicolumn{2}{|c|}{ Age of all 102 Subjects (n=102 including both sexes) } \\
\hline
\end{tabular}

In the present study, reported, physical-dental, radiological and final age of all one hundred and two subjects were analysed. In this, the individuals of wide range of ages (from 10 years to 70 years) are involved.

Age from Tanner staging of pubic hairs of 39 subjects (age between 10 to 16 years, including both males and females) was assessed and that was compared with Reference age for pubic hairs which was taken from UNICEF Manual for Medical Officer (2005),[7] Physical-Dental age, Radiological age and Final age.

In Table No.4, Pearson Correlation and P value between age from Tanner staging of pubic hairs of 39 subjects (age between 10 to 16 years, including both males and females), Reference age for pubic hairs which was taken from UNICEF Manual for Medical Officer (2005),[7] Physical-Dental age, Radiological age and Final age was assessed and analysed. Following observations were found: Reported age shows the highest degree of correlation with Final age (0.8687) and the lowest correlation with Radiological age (0.8364). Reference age for pubic hairs shows highest correlation with final age (0.9104) and the lowest correlation with Radiological age (0.8702). Physical-Dental age shows the highest degree of correlation with Final age (0.9560) and the lowest correlation with Radiological age (0.9298). Correlation between Radiological age and final age was 0.9626. Very strong correlation (0.9104) was observed between Reference age for pubic hairs and final age, which shows that Tanner staging of pubic hairs was a good parameter for estimation of age between 10 to 16 years for both males and females.

\section{DISCUSSION}

The present study represents a basic cross-sectional investigation for age estimation by correlation of physicaldental with radiological findings. There are considerable variations in development of secondary sexual characteristics, teeth eruption and ossification of bones in different regions of the same country. These characteristics are influenced by various factors like geographical location, climate, diet, hereditary, socioeconomic status, habits, etc. In multiethnic country like India, it is difficult to follow single standard data for determination of age for the entire country. Until now, many workers around the world have done a lot of research regarding age estimation based on pubertal changes, eruption of teeth and ossification of bones. Most of the studies in past have taken into consideration one of these three criteria. Considerable discrepancy regarding the age determination by the development of secondary sexual characteristics, teeth eruption and the ossification centres fuse with their respective shafts is observed after perusal of these researches. However, in this study, correlation of all these three criteria are taken together to determine the age of living individuals.

In Table No.1, Reported, Physical-Dental, Radiological and Final age of all 102 subjects were analysed. In this, minimum reported age was 10 yrs. while maximum reported age was 70 yrs. Minimum physical-dental age was 10 yrs. while maximum physical-dental age was 50 yrs. Minimum radiological age was 9 yrs. while maximum radiological age was 55 yrs. Minimum final age was 9.5 yrs. and maximum final age was 55 yrs. So individuals of wide range age (from 
10 yrs. to 70 yrs.) are involved in this study to cover maximum possible subjects.

In Table No.2, where Pearson correlation and $\mathrm{P}$ values between all age variables i.e. Reported age, Physical-Dental age, Radiological age and Final age were analysed, in which each variable was positively correlated with all the other variables. The correlation for the age variables studied showed positive correlation (ranging from 0.9768 to 0.9994 ) between each other. The finding of this study support those of Green LJ (1961),[11] which attempts to establish correlation between dental, skeletal, chronological age, weight and height, finding a stronger correlation between dental and chronological age even than that existing between dental and bone development, Krogman WM (1962)[12] dental developments have been strongly related to skeletal maturation and Helm S (1990)[13] studied the relation between dental and skeletal maturation. He correlated the age estimation between the numbers of emerged permanent tooth and RUS (Radius, Ulna and short bones) method of skeletal maturity scores. His results also showed that the skeletal age, rather than dental maturity alone, would be of important in assessing the age in children of unknown chronological age or any birth record which is against Hagg \& Taranger (1980) ${ }^{[14]}$ study of relationship between dental eruption and maximum pubertal growth, finding a low correlation between somatic and dental development. The lack of concordance among the results of previous studies may be due to the different methods of assessing skeletal and dental maturity.

On review of the correlation in this study (Table No. 2), Very strong correlation was found between Physical-Dental age and Radiological age (0.9961). Positive correlation was found between all these variables. Reported age shows the highest degree of correlation with Radiological and Final age (0.9843) and the lowest correlation with Physical-Dental age (0.9768). Physical-Dental age shows the highest degree of correlation with Final age $(0.9965)$ and the lowest correlation with Radiological age (0.9961). Correlation between Radiological age and final age was 0.9994. Similarly, significant $P$ value (0.0001) was seen between the Reported age, mean of Physical-Dental age, Radiological age and Final age which is consistent with Green LJ (1961).[11]

So considering the height and weight for age estimation, we found significant difference of $11.73913 \mathrm{~cm}$ (Table No.3) between Observed height and Reference height taken from UNICEF manual for Medical Officers (2005),[7] and 12.21739 $\mathrm{kg}$ between Observed weight and Reference weight taken from the UNICEF manual for Medical Officers (2005),[7] as this difference was very significant, which is not consistent with the UNICEF manual for Medical Officers (2005).[7] That is why height or weight alone cannot be considered as good parameter for determination of age.

As per Table No.4, we found very strong correlation and statistically highly significant $p$-value $(p<0.001)$ between Reference age for Tanner stages of pubic hair taken from the UNICEF Manual for Medical Officer (2005),[7] Physical-Dental age, Radiological age and Final age, which shows that Tanner staging of pubic hairs is a good parameter for estimation of age between 10 to 16 years for both males and females.

Comparison between Mean of age from Physical-Dental findings with Mean of Dental reference age, findings here are consistent with UNICEF manual for Medical Officers (2005)[7] and Mathiharan K (2011) ${ }^{[15]}$ mentions that a note should always be made as to whether there is a space behind second molar teeth if third molar is absent. After the eruption of second permanent molar usually at 12-14 years; third molar does not erupt until age of 17 years or later. Considerable posterior jaw growth is required after the age of $12-14$ years to allow room for these teeth. This growth of jaw produces space behind second molar tooth which is appreciable between 14-16 years of age or later. There appears to be a slight indication of a factor composed of physical-dental age and radiological age. We might hypothesise that the factors which control physical-dental age and radiological age are very important in determining chronological age. It should also be pointed out that only evaluations of some physical, dental and radiological findings were obtained in this study. A more complete appraisal of the age-related other physical parameters, evaluation of the microscopy of teeth, radiography for various joints, might improve the degree of correlation between these variables.

As shown in Table No.5, Correlation and P value between Physical-Dental age and Dental reference age taken from the UNICEF Manual for Medical Officer (2005) ${ }^{[7]}$ were calculated, here also, we found very strong correlation and statistically highly significant $p$-value $(p<0.001)$ between Physical-Dental age and Dental reference age. These findings are consistent with the UNICEF Manual for Medical Officer (2005).[7] So we can say that, Dental status is a good parameter for estimation of age for both males and females.

Overall a very strong correlation was observed in between Physical-Dental age and Radiological age.

\section{CONCLUSION}

The following conclusions were derived from the present study about age estimation by correlation of physical- dental with radiological findings:

Height or weight alone cannot be considered as a good parameter for determination of age, this could be due to factors like racial, genetic, socioeconomic, nutritional and climatic factors, which need to be evaluated.

Highly significant $p$-value $(p<0.0001)$ found between Tanner stages of pubic hair development compared with Physical-Dental age, Radiological age and Final age.

Physical findings, dental status and radiological findings are good parameters for estimation of age.

Very strong correlation found between age estimated by Physical-Dental findings and Radiological findings.

Parameters like secondary sexual characters, dental eruption status and ossification status, together gives a more reliable estimation of age as compared to studying them individually.

\section{REFERENCES}

[1] Karmakar RN. JB. Mukharjee's Forensic medicine and toxicology. $3^{\text {rd }}$ edn. 2007:125-30, 135-38, 146, 147, $154,155$.

[2] Schmeling A, Garamendi PM, Prieto JL. Forensic age estimation in unaccompanied minors and young living adults. In: Vieira DN. edr. Forensic medicine - from old problems to new challenges. $1^{\text {st }}$ edn. Germany: InTech 2011: p. 77. 
[3] Ritz-Timme S, Cattaneo C, Collins MJ, et al. Age estimation: the state of the art in relation to the specific demands of forensic practise. Int J Legal Med 2000;113(3):129-36.

[4] Schmeling A, Reisinger W, Geserick G, et al. Forensic age estimation of live adolescents and young adults. In: Tsokos M. edr. En: Forensic Pathology reviews. Forensic Pathology Reviews, Vol 5. Humana Press 2008.

[5] Saunders E. The teeth: a test of age. British and Foreign Medical Review 1838;5:205-7.

[6] Mehta HS. Age determination-medical law and ethics in India. The Bombay Samachar Pvt Ltd., Mumbai. 1963:335-8. (Cited in chapter Personal Identity in Modi's Medical Jurisprudence and Toxicology. edited by Mathiharan K, Patnaik AK. 22nd edn. New Delhi: Butterworths India 2005:263-337).

[7] UNICEF manual for medical officer dealing with medico-legal cases of victims of trafficking for commercial sexual exploitation and child sexual abuse by Department of women and child development, Govt. of India. 2005:41-8.

[8] Marshall WA, Tanner JM. Variations in the pattern of pubertal changes in boys. Arch Dis Child 1970;45(239):13-23.
[9] Camps FE, Robinson AE, Lucas BGB. Changes after death. In: Gradwohl's Legal Medicine. 3rd edn. Chicago: John Wright and sons Publications 1976:78-100.

[10] Karmakar RN. Forensic medicine and toxicology: oral, practical \& Mcq. $3^{\text {rd }}$ edn. Kolkatta: Academic Publishers 2010: p. 11.

[11] Green LJ. The interrelationships among height, weight and chronological dental and skeletal ages. Angle Orthod 1961;31(3):189-93.

[12] Krogman WM, Iscan MY. The human skeleton in Forensic Medicine. $2^{\text {nd }}$ edn. Charles C. Thomas Publisher, Illinois, USA: 1986.

[13] Helm S. Relationship between dental and skeletal maturation in Danish School children. Scand Journal of Dent Res 1990;98(4):313-7.

[14] Hagg U, Taranger J. Skeletal stages of the hand and wrist as indicators of the pubertal growth spurt. Acta Odontol Scand 1980;38(3):187-200.

[15] Mathiharan K, Kanan K. Modi's medical jurisprudence \& toxicology. 24th edn. New Delhi: Lexis Nexis 2011:277-308. 